\title{
The Development of Generalized Trust among Young People in England
}

\author{
Jan Germen Janmaat
}

Department of Education, Practice and Society, Institute of Education, UCL, London WC1H 0AL, UK; g.janmaat@ucl.ac.uk

Received: 26 August 2019; Accepted: 21 October 2019; Published: 25 October 2019

\begin{abstract}
This paper explores how generalized trust develops over the life course among young people in England and whether trust is influenced more by family background factors or by conditions in late adolescence and early adulthood. If the latter are important, there may be reason for concern about falling levels of trust as material conditions, particularly regarding housing, have deteriorated for the present generation of young people. The first set of influences are highlighted by a perspective arguing that trust is primarily shaped by conditions in early childhood, while the latter are suggested by the so-called social learning perspective, which claims that people continuously adjust their social trust through interactions with people in different contexts. Analyzing data of the Citizenship Education Longitudinal Survey, the study finds that trust remains quite volatile until the early twenties. It declines between ages 16 and 23 and groups differing in educational attainment, civic participation and housing situation start to drift apart in their levels of trust between these ages. Educational attainment, civic participation and housing, as conditions pertaining to late adolescence and early adulthood, also turn out to have a significant impact on trust at age 23 controlling for trust at age 16. However, while the first two conditions are influenced by trust at age 16, housing (tenure) is not, indicating it is a more exogenous factor. Family background factors are not influential. Not only do these findings support the social learning perspective, they also suggest that poor living conditions depress trust among a significant minority of young people and exacerbate disparities of trust.
\end{abstract}

Keywords: generalized trust; adolescents; life course; early socialization; social learning; educational attainment; living conditions; widening disparities

\section{Introduction}

Opportunities and material conditions are not the same for different generations of young people growing up in Britain. Young people today face other challenges than their parents when they were young. In the area of education there are certainly more opportunities for today's youth to acquire high level qualifications, but when it comes to housing it has become much more difficult for the current cohort of young people to find affordable and secure accommodation in areas where the jobs are. Home ownership has increasingly become an unattainable ideal for young people (Howker and Malik 2013). In terms of the labour market, it is easier for today's youth to find work but it is more difficult for them to acquire a permanent contract or to find work that matches their qualifications. Many young people, particularly of disadvantaged backgrounds, are stuck in low-paid, part-time and insecure jobs, leading some observers to characterize their situation as precarious and one of downward social mobility (King 2015; Shildrick et al. 2012).

This article examines young people's expressions of trust in the unknown other in light of these changing circumstances. There are good reasons to focus on this variety of trust, on the influence of material conditions in early adulthood, and on young people as object of research. First, generalized trust, i.e., trust in people you do not know, is a key social asset as it has been linked 
with all kinds of benefits at both the individual and societal level, including better health, higher levels of civic and political participation and economic growth (Knack and Keefer 1997; Putnam 1993; Uslaner and Brown 2005; Abbott and Freeth 2008; Bjørnskov 2012). Generalized trust has these positive effects because it reduces transaction costs and enhances cooperation (Hardin 1999). Because of this particular propensity, it has been labelled as the "resource that oils the wheels of the market economy and democratic politics" (Stolle 2003, p. 19). Second, although the debate about the most influential determinants of generalized trust is continuing, (changes) in socio-economic conditions during adulthood have been proposed as important drivers of trust in other people. Unemployment and job displacement (i.e., losing one's job due to redundancy, downsizing and restructuring) have for instance been found to significantly reduce social trust (Lindström 2009; Laurence 2015). Similarly, obtaining a college degree has been shown to be influential by enhancing trust in other people (Huang et al. 2011). In view of the increasingly desperate situation on the housing market, with many young people being forced to rent privately at unfavourable conditions, tenure might also be related to generalized trust, a condition that has largely been overlooked by academia. Third, young people in Britain are an interesting group to look at since their levels of generalized trust are lower than in any other age group (Janmaat 2016, p. 273). They moreover experienced the steepest decline in generalized trust from 2006 to 2009 (Green et al. 2011, p. R14), which may be due to the economic crisis having disproportionately affected this age group (Pilkington and Pollock 2015). These patterns and trends are part of a long-term decline in generalized trust from the end of the 1950s to the mid-2000s among the British population as a whole (Green et al. 2011, p. R12).

In view of these considerations we aim to investigate in this article whether the socio-economic conditions mentioned above influence the development of generalized trust among young people in Britain today. If they do, we might expect trust levels to fall during late adolescence and early adulthood in view of the difficult material conditions (as described above) that many young people face at present. To our knowledge no other study has specifically looked at the effect of these conditions among this age group. Our study will thus contribute to the literature on whether, and if so, how, experiences in late adolescence and early adulthood shape generalized trust. This is a pertinent and perhaps rather provocative line of inquiry in view of the prevailing belief that generalized trust is primarily shaped by early childhood socialization and is largely set by the time children reach puberty (as explained further below). More precisely, we explore the following questions:

1. What is the level of generalized trust among young people in Great Britain today and how does that relate to other kinds of social trust?

2. How has generalized trust developed over the life course of the current generation of young people?

3. How influential are socio-economic conditions experienced during early adulthood by comparison to other factors shaping generalized trust among young people?

We begin by delving more deeply into the phenomenon of generalized trust and its relations to other forms of social trust. Subsequently we discuss a number of perspectives on the roots and drivers of generalized trust. We identify a perspective arguing that trust continues to be shaped by social interactions throughout the life course (the so-called social learning perspective) and contrast this to the argument, outlined above, that trust takes on a definite shape early in life. We will explain that the influence of the material conditions noted above can be understood through the lens of the social learning perspective by discussing the causal mechanisms linking these conditions to generalized trust. We then address the research questions in the order listed above. We further note that we cannot explore the proposed mechanisms with the data at our disposal; we can only assess whether the socio-economic conditions of late adolescence are related to generalized trust and whether these links are stronger than those of other factors.

We find that trust remains quite volatile during adolescence. Between ages 16 and 23 disparities in trust appear to widen across groups defined by highest level of education, degree of civic participation 
and housing situation. Educational attainment, civic participation and tenure also show significant relationships with trust at age 23 , controlling for trust at age 16 , while family background factors show no significant links. The findings thus support the social learning perspective. More broadly they suggest that the precarious conditions that young adults experience in Britain today dampen their trust in other people and lead to a widening of the trust gap between the disadvantaged and the privileged.

\section{Generalized Trust: What Is It and What Influences It?}

\subsection{Defining the Concept}

Trust has been defined as the perceived likelihood that others, "at worst, will not knowingly or willingly do you harm, and at best, will act in your interests" (Gambetta 1988, p. 78). The sub-variety of generalized trust has been described as the core value or belief that other people can and should be trusted (Uslaner 2002; see also Green et al. 2011; Delhey and Newton 2003). It has been contrasted with strategic or particularized trust which is directed at people we have daily encounters with, such as family, friends, colleagues and acquaintances (Hardin 1999; Putnam 2000; Uslaner 2002). While the latter is a rational response to the behaviour of others and can be quite volatile, generalized trust is more stable and less affected by social context. Generalized trust is directed outwards and can therefore be seen as an important component of bridging social capital (Putnam 2000). A key indicator of generalized trust is the well-known survey item "most people can be trusted", which has been found to tap into a syndrome that can be labelled "trust in strangers" along with other items asking about trust in people one does not know (Uslaner 2002, p. 54). In contrast, particularized trust is indicated by questions about people we know well, such as family, people at work and people you know from the local church or club. These questions also form a coherent syndrome of attitudes (ibid.).

\subsection{Explaining Generalized Trust}

Many different explanations have been offered in the literature to account for variations across individuals and across time and space in generalized trust. These perspectives have highlighted factors operating at different levels-micro (individual), meso or macro. We will only discuss those suggesting individual level determinants as these are the factors we can address with our data. Among these theories, some focus on conditions prevailing in early childhood while others highlight events and processes occurring later in life. Focusing on different life stages, these theories are of obvious relevance for this article. If generalized trust is mostly the product of early childhood socialization and changes little thereafter, the material circumstances and opportunities experienced during early adulthood, as the focus of this article, will not play much of a role in influencing trust.

Scholars emphasizing early childhood as the key formative period for generalized trust consider parent-child interactions as crucial (e.g., Wuthnow 1997; Uslaner 2002). Caring parents, according to Uslaner, instill a feeling of self-confidence in their children, making them less anxious in their contacts with other people. They also lead by example: "Parents who are trusting, tolerant, and involved in their communities are role models leading children to trust" (ibid., p. 93). By learning to trust their caregiver, children develop the belief that human beings in general are trustworthy, responsible and dependable and carry this disposition with them for the rest of their lives (Wrightsman 1992). This early childhood socialization perspective also broadly includes studies emphasizing the importance of social background. Children growing up in affluent families are less likely to be a victim of crime and abuse, which have been identified as particularly negative influences on trust (Ferraro 1995), and are more likely to develop a lasting optimistic outlook in life, including a perception that other people are trustworthy and benevolent (Brehm and Rahn 1997). ${ }^{1}$

1 It should also be noted that a recent strand in the literature has explored whether and to what extent trust has a genetic basis (Hirashi et al. 2008; Sturgis et al. 2010; Oskarsson et al. 2015). Sturgis et al. (2010), for instance, found that a majority of the variation in social trust can be explained by a genetic factor. We neither challenge these findings nor engage with this 
Others have argued that generalized trust is also shaped by experiences later in life. Glanville and Paxton (2015) have coined this view the social learning perspective. A key assumption of this perspective is that people continuously adjust their trust in others through interactions with various people in different contexts. As Stack $(1978$, p. 563) put it: "Each individual encounters a variety of others who treat him positively or negatively, who keep their promises or do not. Each person generalizes from these past experiences in the process of developing expectancies about how the next person will treat him". As experiences vary across different social domains, people's levels of trust depend on social context. Generalized trust is the average outcome of all these different experiences (Rotter 1971). Glanville and Paxton (2015) analyses of the Social Trust Survey data primarily support the social learning perspective as they find that people develop trust through their interactions with different groups of people.

The social learning perspective can be said to broadly incorporate all approaches emphasizing specific conditions and experiences during adolescence and adulthood as key drivers of generalized trust. This is because the causal narratives of these approaches all point to social interactions as a key mechanism through which a highlighted condition influences trust, as discussed in further detail below. Conditions that have received a lot of attention in the literature include participation in all kinds of associations (aka the social capital approach) and educational attainment. Research on the influence of employment and tenure has been notably sparser.

The approach that has no doubt attracted the greatest amount of attention is the social capital theory as advanced by Putnam $(1993,2000)$. It postulates that participation in organizations and networks generates norms of reciprocity and cooperation through social interactions with other members. These norms in turn command and thus foster generalized trust and other civic qualities such as tolerance, a sense of moderation and public spiritedness. Social capital can be said to operate both at the individual level, by making individuals who participate more trusting, and at the meso level by enhancing the trust levels of both participants and non-participants in communities with dense social networks. In other words, social capital has positive externalities making it similar to a public good (Putnam 2007). A wealth of research has explored these assumptions, particularly the link between individual-level participation and trust. The results have been mixed. Some find a strong link between membership in civic associations and generalized trust (e.g., Brehm and Rahn 1997; Stolle and Rochon 1998). However, as these studies relied on cross-sectional data they could not determine the direction of causality (Sturgis et al. 2012). This is important for the link between participation and trust as it makes sense to expect a reverse effect as well, i.e., of more trusting people being more inclined to become active participants. Studies relying on longitudinal data with repeated measures of both outcomes and predictors are able to assess reverse causality and they have generally not been as supportive of social capital theory. Controlling for prior levels of trust, Claibourn and Martin (2000), Li et al. (2005) and Sturgis et al. (2012), for instance, have not found a link between membership in voluntary organizations and subsequent levels of generalized trust.

Social capital theorists, however, point out that not just any social networks will yield generalized trust but only those that are open and that interconnect a wide variety of people (i.e., 'bridging' social capital) (Putnam 2000; Burt 2005). Closed networks consisting of strong ties between very similar people ('bonding' social capital), in contrast, may enhance particularized trust but could be detrimental to generalized trust. In agreement with this claim, Paxton (2007) found that membership in connected associations, as opposed to membership in isolated associations, is linked to higher levels of generalized trust. In further support of this conjecture, and using longitudinal data, Lopaciuk-Gonczaryk (2019) found an increase in generalized trust to be linked with an expansion of the network of acquaintances (i.e., bridging social capital) and a decrease in the family and friends network (bonding social capital).

literature in greater depth because we are primarily interested in environmental influences on trust, i.e., influences that can be changed through interventions. Even if most of the variation in trust could be explained by nature, that still leaves a considerable part to be accounted for by factors amenable to manipulation. 
Education has been argued to foster generalized trust by enhancing people's cognitive skills and by inculcating trust as a social norm. Better cognitive skills enable people to process more information and interpret the behaviours of others more accurately, making the actions of other people and the interactions with them more transparent and predicable (Knack and Keefer 1997; Knack and Zak 2002). The socialization function of education concerns teaching young people to have an open mind to other people, to believe in their trustworthiness and to treat them with respect (Bjørnskov 2007; Stubager 2008). The longer individuals stay in the education system, the more they are socialised in these norms. There is also strong empirical evidence for the idea that individual educational attainment enhances generalized trust. In a meta-analysis of 28 studies, Huang et al. (2009), for instance, found that one additional year of schooling increases generalized trust by $4.6 \%$ of a standard deviation.

Having a rewarding and well-paid job is also seen as conducive to trust. Work of this kind offers people economic and social status, which can be said to foster generalized trust in several ways. First, it allows individuals to take greater risks and incur greater losses, which are a precondition for placing trust in people one does not know (Laurence 2015). Second, and more relevant from the social learning perspective with its focus on social interactions, a well-regarded job commands respect and better treatment from others, leading to higher levels of self-esteem and to more positive opinions about other people (Paxton 1999; Delhey and Newton 2003). Work further offers a social network in which norms of social trust, cooperation and reciprocity can thrive (Putnam 2000) (see the discussion of social capital above). Consequently, being unemployed or losing one's job have been linked with lower life satisfaction, declining self-confidence and greater anxiety (Waters 2007), frames of mind that have been identified as strong drivers of distrust (Paxton 1999).

To our knowledge, there are no studies linking tenure (i.e., owning one's own home; renting privately or from the council; living with parents) specifically to generalized trust, but the argument that homeownership creates better citizens is well established in the literature. This argument is based on the idea that home owners have more incentives to get involved in local community life as the value of their homes depends directly on the quality of the neighbourhood (DiPasquale and Glaeser 1998). Thus, to the extent that participating in local networks fosters trust through social interactions (see the discussion of social capital above), homeownership could be related to higher levels of generalized trust. Participation in neighbourhood activities and civic participation in general have indeed been found to be higher among homeowners than tenants controlling for socio-demographic factors and neighbourhood characteristics (Manturuk et al. 2010). In contrast to that of homeowners, the social networks of tenants renting from the local council are often portrayed as detrimental to social cohesion. Policy discourses characterize these networks as typical of socially disadvantaged people more broadly and as consisting of tight-knit groups (i.e., bonding social capital) that foster norms of worklessness, exclusion and hostility to the wider society (Tyler 2013; Matthews and Besemer 2015). It might further be postulated that homeownership fosters generalized trust by giving home owners the sense of security and material resources to reach out and take risks. Conversely, the insecurity experienced by tenants renting privately, who can be evicted from their homes with a two months notice by their landlords, may well contribute to a sense of anxiety and distrust.

The issue of reverse causality is also relevant with respect to three last-named conditions. It makes, for instance, sense to expect that trust helps to gain higher qualifications, find better work and buy a property. In the empirical analyses that follow we will use the CELS longitudinal data with repeated measures of trust, enabling us to address this problem. 


\section{Data Sources, Variables and Methods of Analysis}

\subsection{Data Sources}

We explore the three research questions with two data sources. We used the LLAKES Youth survey conducted in June-July 2014 to address the first research question. This nationally representative, cross-sectional web-based survey collected data among 2025 young people aged 22-29 in England, Scotland and Wales, but we only used the data for England. The last two research questions have been explored with the Citizenship Education Longitudinal Survey (CELS), which was held among young people in England. This study includes panel data from a cohort of youngsters who were aged 11 and 12 (Year 7; first year of secondary school) when they were surveyed for the first time (in 2002-2003). Subsequently, this group was surveyed every two years until 2011. The last wave was collected in 2014 when respondents were 23 years old. The data from the first wave was collected from a nationally representative sample of 75 state-maintained schools-representative in terms of region, GCSE attainment and percentage of students on free school meals (Benton et al. 2008). Within the sampled schools all the students of the year of interest were selected (i.e., all the students in a certain grade). The current study uses data from Waves 1 (ages 11-12), 3 (ages 15-16), 5 (ages 19-20) and 6 (age 23).

CELS is no different from other longitudinal datasets in showing considerable attrition. While the study started out with 18,583 respondents in Wave 1,38\% of this original sample participated in Wave 3 and just 2.3\% (426 respondents) did so in Wave 6. Each wave was also topped up with samples from disadvantaged and minority groups, however, and some of these respondents continued to participate in later waves. Thus, of the 13,378 respondents in the third wave, 596 (4.5\%) participated in Wave 6. Obviously, with such a high level of attrition we cannot possibly claim that the analytic sample will be nationally representative, all the more so as this attrition is selective: those who continued participating are on average from more privileged backgrounds and have higher levels of civic engagement than those who dropped out. Moreover, attrition may have occurred on a number of unobserved variables as well. However, the data is still useful as the respondents who participated in all the waves show sufficient variation on the dependent variable (trust in people of one's own age) and a number of independent variables (see further below). Thus, the attrition has not been so selective that only the very trusting respondents from only very educated backgrounds have continued participating in all the waves. To offer further reassurance, any bias produced by attrition can be mitigated by including the variables producing the selective unit non-response in the analyses as control variables (cf. Paterson 2013, p. 29), which we will consequently do. What is more, several studies have shown that selective attrition affects aggregate levels of outcomes but hardly matters for relationships between predictors and outcomes (e.g., Alderman et al. 2001; Wolke et al. 2009). We are primarily interested in the latter. When, in the following, we present trends in trust based on aggregate levels, we will highlight the limits in terms of representativeness.

\subsection{Variables}

In this section we explain the variables that have been used in the analyses to address the third research question. These analyses are based on respondents participating in Wave 3 and 6 of CELS $(\mathrm{N}=596)$. The variables included as explanatory variables in the analyses represent the conditions in early childhood or later in life that the literature review has identified as important determinants of generalized trust.

We measure generalized trust, our key dependent variable, with the Wave 6 item "How much do you trust the people around you?-people of your own age". For reasons outlined in the third paragraph of the results section below we consider this to be an acceptable indicator of generalized trust. The responses to this item were measured on a four-point scale and show a fairly balanced variation approaching a normal distribution: 'not at all' (3.9\%); 'a little' (35.9\%); 'quite a lot' (54.9\%); 'completely' (5.3\%) (see also Table 1). 
Table 1. Descriptive statistics of the dependent and independent variables.

\begin{tabular}{|c|c|c|c|}
\hline Variable & Category $(\%)$ & Wave & Valid N (\%) \\
\hline \multicolumn{4}{|l|}{ Dependent } \\
\hline Generalized trust & & 6 & $585(98.2)$ \\
\hline Not at all & 3.9 & & \\
\hline A little & 35.9 & & \\
\hline Quite a lot & 54.9 & & \\
\hline Completely & 5.3 & & \\
\hline \multicolumn{4}{|l|}{ Independent } \\
\hline Education mother & & 6 & $493(82.7)$ \\
\hline Left full time education at 15 or 16 & 52.1 & & \\
\hline Left after college or sixth form & 28.2 & & \\
\hline Studied at university/got a degree & 19.7 & & \\
\hline Education father & & 6 & $492(82.6)$ \\
\hline Left full time education at 15 or 16 & 56.9 & & \\
\hline Left after college or sixth form & 23.4 & & \\
\hline Studied at university/got a degree & 19.7 & & \\
\hline Books at home & & 3 & $591(99.2)$ \\
\hline 0 books & 2.2 & & \\
\hline $1-10$ books & 10.2 & & \\
\hline $11-50$ books & 22.3 & & \\
\hline $51-100$ books & 20.6 & & \\
\hline 101-200 books & 18.6 & & \\
\hline More than 200 books & 26.1 & & \\
\hline Ethnic background & & 6 & $593(99.5)$ \\
\hline Asian & 10.5 & & \\
\hline Black & 1.5 & & \\
\hline White British & 84.5 & & \\
\hline Other & 3.5 & & \\
\hline Educational attainment * & & 6 & $595(99.8)$ \\
\hline Level 1 & 5.0 & & \\
\hline Level 2 vocational & 5.7 & & \\
\hline Level 2 academic (GCSE: 5 A to Cs) & 10.3 & & \\
\hline Level 3 vocational (NVQ or Btech) & 13.8 & & \\
\hline Level 3 academic (A levels) & 10.8 & & \\
\hline Level 4 vocational & 7.4 & & \\
\hline Degree or higher & 45.9 & & \\
\hline Other qualifications & 1.2 & & \\
\hline Tenure & & 6 & $590(99.0)$ \\
\hline Social rent, living independently & 5.1 & & \\
\hline Private rent, living independently & 18.3 & & \\
\hline Owner, living with parents & 41.4 & & \\
\hline Renting, living with parents & 11.9 & & \\
\hline Owner, living independently & 8.8 & & \\
\hline Other living arrangement & 14.6 & & \\
\hline Current activity & & 6 & $596(100.0)$ \\
\hline Working & 80.9 & & \\
\hline In education & 7.7 & & \\
\hline Something else & 11.4 & & \\
\hline
\end{tabular}


Table 1. Cont.

\begin{tabular}{llll}
\hline Variable & Category (\%) & Wave & Valid N (\%) \\
\hline Active civic participation & & 6 & $596(100.0)$ \\
In none of these clubs/groups & 49.5 & & \\
In one of these clubs/groups & 37.4 & & \\
In two of these clubs/groups & 10.9 & & \\
In three of these clubs/groups & 2.0 & & \\
In four of these clubs/groups & 0.2 & $696(100.0)$ \\
\hline Control variables & & & \\
\hline Gender & & & \\
Boy & 48.0 & 3 & \\
Girl & 52.0 & & \\
\hline Generalized trust & & & \\
Not at all & 4.8 & & \\
A little & 29.8 & & \\
Quite a lot & 55.0 & & \\
Completely & 10.3 & & \\
\hline
\end{tabular}

* The categories of this variable have been based on the National Qualifications Framework (http://www.thegrid.org. uk/learning/1419/curriculum/national/).

Our main independent variables tap social background, ethnic background, educational attainment, tenure, current activity and active civic participation. Social background was measured with three variables representing Wave 6 items on parental education level [response categories: 1 = 'left full time education at 15 or 16'; 2 = 'left after college or sixth form'; 3 = 'studied at university/got a degree'] and a Wave 3 item on the number of books at home [six point scale ranging between $1=$ ' 0 books' and $6=$ '200 books']. These items are standard measures of SES and have been shown to be influential drivers of youth civic attitudes including trust (Schulz et al. 2010). Ethnic background was measured with the Wave 6 item "how would you describe yourself?" [1 = Asian or British Asian; 2 = Black or Black British; 3 = White British; 4 = Other]. Educational attainment was measured with a variable based on a Wave 6 item on highest qualification achieved (see Table 1 for the categories). We tapped tenure with a variable based on two Wave 6 items capturing both tenure as such and living arrangement to account for the fact that many young people at age 23 still live with their parents (see Table 1 for its categories; 'social rent' refers to renting from a council at below market prices; 'private rent' concerns renting from a private landlord at market prices). Current activity is tapped with the Wave 6 item "which of the following best describes the MAIN thing you are currently doing?" [ $1=$ working; $2=$ in education; 3 = doing something else]. Active civic participation is measured with a variable based on the Wave 6 item "in the last year, have you taken part in any of the following clubs or groups?". This item lists nine very different clubs and groups, including environmental, human rights, sports, arts and drama, student union and trade union groups. The variable measures the number of different clubs or groups a respondent has taken part in. It represents a scale ranging between $0=$ 'none of these' and $4=$ 'in four of these'.

We further include two control variables in the analysis: gender [ $1=$ male; $2=$ female $]$ and prior trust (Wave 3 "people of your own age"). It is important to control for prior trust to address issues of selection relating to conditions of late adolescence and early adulthood. If people who are more trusting in the first place self-select into particular educational pathways or forms of tenure, the influence of educational attainment or tenure on trust merely reflects self-selection and does not constitute a genuine effect.

Table 1 below provides basic descriptive statistics of all the variables. Only the variables education mother and education father have quite high levels of missing values (17.3\% and $17.4 \%$ respectively). Records are complete or almost complete on all the other variables. The statistics illustrate the cross-generational educational expansion in England. While nearly half of the respondents said they 
obtained a degree (45.9\%), less than 20 percent of their parents completed higher education, and more than 50 percent of parents left education after age 16. We further see that the vast majority of the respondents are in work $(80.9 \%)$ and that a small majority is still living with their parents $(53.3 \%)$. Some have already bought their own homes $(8.8 \%)$ but there are more who are renting privately $(18.3 \%)$. Almost $50 \%$ do not participate in any group or club while a further $37.4 \%$ take part in just one club or group.

\subsection{Methods of Analysis}

We use a variety of methods to explore the three research questions, including basic descriptive analyses, correlations, principle component analysis, linear regression and logistic regression. When exploring the determinants of generalized trust, we used linear regression and not ordered logistic regression despite the ordinal nature of the dependent variable. We did so because the coefficients of linear regression are easier to interpret. Nonetheless we carried out ordered logistic regression as a robustness check (see footnote 2). The data moreover permit the use of linear regression because the distribution of responses on the dependent variable is not overly skewed (as shown by Table 1) and a test on the residuals of models including all the independent variables shows that these residuals are normally distributed. Linear and logistic regressions were conducted in Mplus; all other analyses were carried out with SPSS. The regressions were carried out with imputed data to prevent data loss due to missing values on variables such as education mother and father. To impute data, we used the Bayesian estimation technique of multiple imputation in Mplus (see Muthen and Muthen 2009). This procedure uses all the variables in the model (both independent and dependent ones) to impute the missing values of the variables specified as candidates for imputation; it creates 10 datasets with imputed values and averages out the parameter estimates over a set with the same number of analyses. Finally, because the CELS Wave 3 sample was nested, with respondents selected in grades (and grades in schools), the observations are not independent. We accounted for this bias in our analyses by selecting the robust maximum likelihood estimator and using the school grade variable to indicate the clustering of the data (see Muthen and Muthen 2009).

As noted above, we will include prior levels of trust in the linear regression model to assess whether the effects of the conditions pertaining to late adolescence and early adulthood are not merely representing self-selection. However, even if these conditions show significant effects after controlling for prior trust, we still cannot claim that these effects are causal as they may proxy for unobserved influences. Only research using experimental designs can establish causality. Thus, panel data with repeated measures of the outcome (such as the CELS data used for this paper) permit a more accurate assessment of explanatory conditions affected by self-selection but researchers cannot conclusively prove causality with such data.

\section{Results}

\subsection{Levels and Interrelations of Different Forms of Trust}

Let us first assess how generalized trust relates to other forms of social trust in terms of both overall levels and interrelations. The LLAKES Youth Survey includes questions on trust in a number of groups, including family, neighbours, and people you meet for the first time, in addition to the well-known "most people can be trusted" item tapping generalized trust. We see that the level of generalized trust is quite low by comparison to trust in people one interacts with on a daily basis: while only $36.4 \%$ stated that most people can be trusted, as many as $62.2 \%$ and $90.8 \%$ expressed high levels of trust in colleagues and family members, respectively (Table 2). Interestingly, trust in people you meet for the first time and trust in people of a different nationality or religion are not very high either. Thus people in general express much higher levels of trust in people they know well than in strangers or people they do not know well, which should not surprise us. 
Table 2. Levels of trust in different groups of people.

\begin{tabular}{lcc}
\hline & $\begin{array}{c}\text { How Much Do You Trust the People } \\
\text { Around You? }\end{array}$ & $\begin{array}{c}\text { Generally Speaking, Would You Say That } \\
\text { Most People Can Be Trusted or You Cannot } \\
\text { Be Too Careful in Dealing with People? }\end{array}$ \\
\hline 'Quite a Lot' and 'Completely' (\%) & 'Most People Can Be Trusted' (\%) \\
\hline Your family & 90.8 & \\
Your colleagues & 62.2 & \\
Your employer & 55.6 \\
People of your own age & 53.9 \\
People of a different nationality & 46.7 \\
Your neighbours & 46.0 \\
People of a different religion & 43.7 \\
People you meet for the first time & 21.6 & \\
& & \\
\hline
\end{tabular}

These patterns are confirmed when we look at relations between the different forms of social trust. All these forms show strong positive correlations with generalized trust (Table 3). In other words, the more you trust your own family, the more you also state that most people can be trusted. However, the generalized trust item correlates notably higher with the items tapping trust in strangers and in members of outgroups. These results thus support the observation by Uslaner (2002) noted above that generalized trust is largely synonymous with trust in strangers.

Table 3. Correlations between different forms of social trust.

\begin{tabular}{ll}
\hline & Generalized Trust \\
\hline Your family & $0.16^{* * *}$ \\
Your employer & $0.25^{* * *}$ \\
Your neighbours & $0.29^{* * *}$ \\
Your colleagues & $0.30^{* * *}$ \\
People of your own age & $0.31^{* * *}$ \\
People of a different religion & $0.37^{* * *}$ \\
People of a different nationality & $0.38^{* * *}$ \\
People you meet for the first time & $0.44^{* * *}$ \\
\hline
\end{tabular}

$$
{ }^{*} p<0.05 ;{ }^{* *} p<0.01 ;{ }^{* * *} p<0.001 \text {. }
$$

We apply reliability analysis and principle component analysis (oblimin rotation) to delve deeper into these interrelationships. Reliability analysis shows that the nine trust items have an alpha value of 0.86 , indicating that they in fact form a highly coherent syndrome of social trust. Yet, this high internal consistency does not rule out the existence of sub-dimensions, as the principle component analysis produces a two factor solution (Table 4). We see that the items on trust in family, colleagues and employer have higher loadings on the second factor while all the other items, including "most people can be trusted", load higher on the first factor. These results thus provide further evidence of the existence of an outward/generalized (Factor 1) and a particularized (Factor 2) variety of trust. Of particular interest is that trust in people of one's own age is more part of the first than the second factor (the factor loadings are 0.67 and 0.44 , respectively) indicating it has more in common with the generalized than the particularized variety. This is important to note as this item, unlike the most people can be trusted item, has been asked repeatedly in the CELS study. We will thus use it as a broad indicator of generalized trust in our analyses on the development and determinants of trust further below. It is worth noting that our findings are in line with Uslaner (2002, p. 54) who found trust in people of your own age to be positively correlated with a 'trust in strangers' dimension (representing generalized trust) and negatively with a 'trust in friends/family' dimension (reflecting particularized trust). Nonetheless we recognize that this indicator of generalized trust is not ideal and we come back to this issue in the concluding section. 
Table 4. Factor loadings of a principle component analysis on nine indicators of social trust.

\begin{tabular}{lll}
\hline & Factor 1 & Factor 2 \\
\hline Your family & 0.17 & 0.81 \\
Your colleagues & 0.59 & 0.70 \\
Your employer & 0.60 & 0.61 \\
Your neighbours & 0.66 & 0.49 \\
People of your own age & 0.67 & 0.44 \\
People you meet for the first time & 0.81 & 0.22 \\
People of a different nationality & 0.84 & 0.27 \\
People of a different religion & 0.84 & 0.25 \\
Most people can be trusted & 0.63 & 0.15 \\
Correlation Factor 1 $\times$ Factor 2: 0.32 & & \\
\hline
\end{tabular}

\subsection{The Development of Generalized Trust over the Life Course}

The CELS longitudinal study allows us to assess how trust develops in individuals as they grow older. Is trust stabilizing at a very early age, as expected by the early childhood perspective, or does it remain volatile into adulthood, which would be more in line with the social learning theory? Figure 1 below shows trends in aggregate levels of trust in people of one's own age between ages 11 and 23. It presents a trend line for the total number of respondents participating in each wave (including top-up samples) and for the respondents participating in all of the waves mentioned. The latter is the true longitudinal sample (numbering 431 individuals) and constitutes only a subset of the former. We applied pre-prepared weights to the former to make the sample nationally representative. Trust appears not to be stable during adolescence: it peaks at age 16 and then declines to initial levels at age 20. The longitudinal sample shows higher levels of trust than the total sample at all ages indicating that it may be selective. Analysis of attrition shows that the longitudinal sample indeed has higher levels of parental education and cultural resources than the latter.

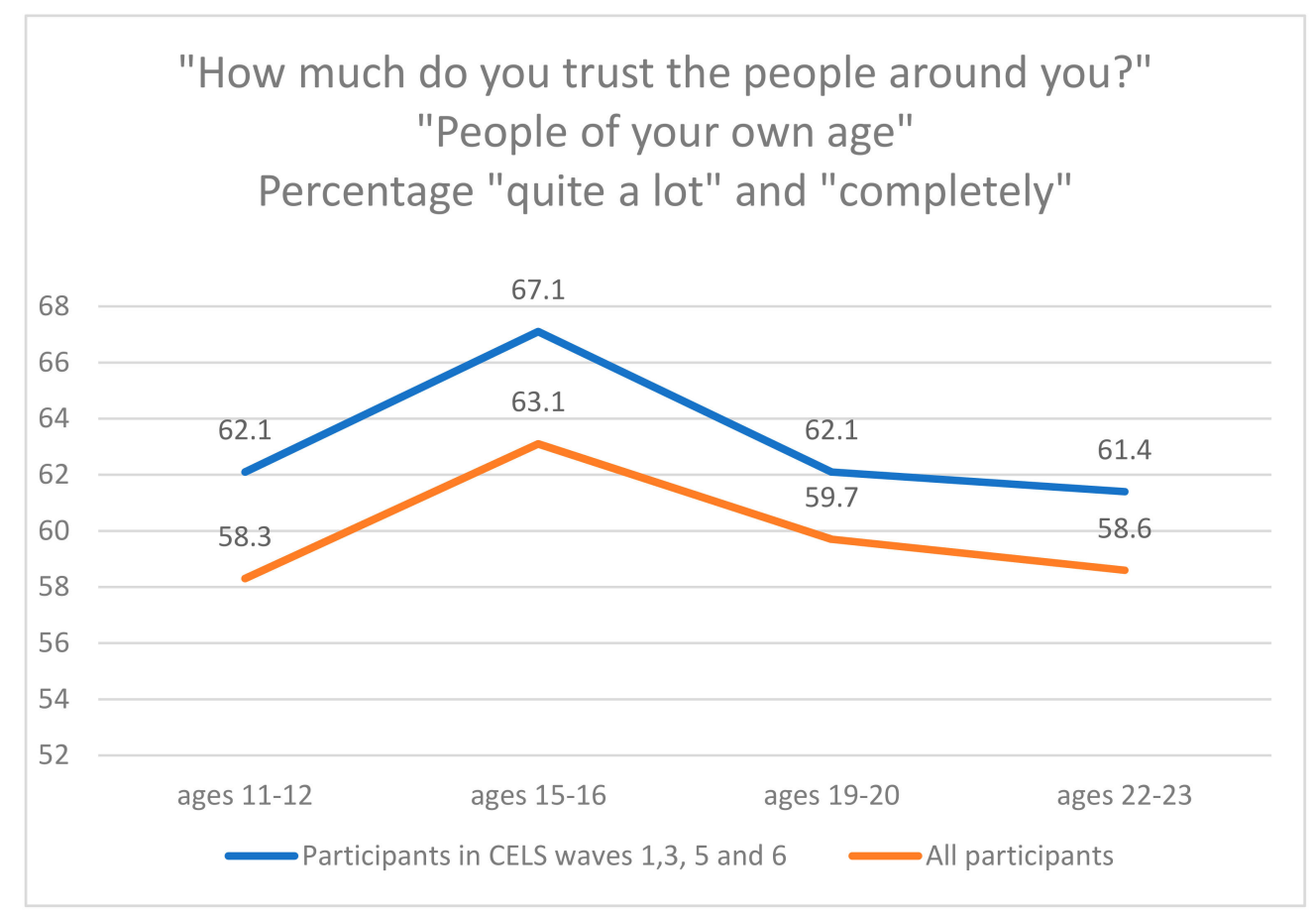

Figure 1. The development of trust in adolescence and early adulthood.

A better way to assess the volatility of trust is to correlate the trust measures at various ages with one another using the longitudinal sample. The stronger the correlation between two consecutive ages, 
the more trust has stabilized. Based on this logic we find that trust is anything but stable between ages 12 and 16, as indicated by the insignificant correlation. After mid adolescence trust becomes progressively more stable, to the point that trust at age 20 explains $12.7 \%$ of the variation in trust at age 23 (Table 5). Yet, even though trust in early adulthood has become more stable, the vast majority of the variance of trust at age 23 is not accounted for by previous trust levels, indicating that experiences during early adulthood still have the power to influence trust. These results thus do not support the perspective claiming that trust is formed definitively during early childhood.

Table 5. Correlations between trust measures at different ages.

\begin{tabular}{lll}
\hline & Correlation & Explained Variance $(\%)$ \\
\hline Trust age $12 \times$ trust age 16 & 0.09 & 0.5 \\
Trust age $16 \times$ trust age 20 & $0.28^{* * *}$ & 7.5 \\
Trust age $20 \times$ trust age 23 & $0.36^{* * *}$ & 12.7 \\
\hline & $* p<0.05 ;{ }^{* *} p<0.011^{* * *} p<0.001$.
\end{tabular}

\subsection{The Determinants of Generalized Trust}

Is trust amongst young adults primarily the product of conditions in early childhood or has it been influenced mainly by more recent experiences and circumstances? We investigate this question by focusing on trust in people of one's own age among 23 year olds and assessing whether indicators of social and ethnic background, such as parental education, number of books at home and subjective ethnic identity, show a stronger link than educational attainment, tenure, active civic participation and current activity. While the former can be said to represent early childhood conditions the latter reflect more recent circumstances. As the influence of the former on trust may have run through the latter, we proceed with the analyses in a stepwise fashion in order to draw correct inferences regarding the effects of these conditions. Table 6 therefore presents three models: Model 1 includes all the determinants of trust; Model 2 includes only the early childhood conditions, enabling us to check whether the recent circumstances merely represent conditions mediating the effect of early childhood conditions; Model 3 includes all determinants and a prior measure of trust. Including this measure allows us to control for trust levels before the conditions of late adolescence and early adulthood (henceforth 'later conditions') come into effect. The most appropriate measure is trust at age 16 since young people lead very similar lives until that age but enter different pathways soon after. Those who continue in education specialize by taking the academic (A levels) or vocational track (NVQ, B Tech), while those who leave school altogether start to work or do something else. Although the vast majority will continue to live with their parents, some start to live by themselves and this number will be growing as people enter their twenties. Controlling for trust at age 16 (i.e., including an autoregressive component in the model) allows us to assess whether the effects of these changing conditions on trust at age 23 merely reflect those of pre-existing trust or whether these conditions exert an independent influence on the development of trust post 16 (cf. Finkel 1995). Finally, Table 7 shows the impact of social and ethnic background and prior levels of trust on the recent circumstances, allowing us to assess reciprocal causation: do these circumstances exert a truly exogenous effect on trust or are they in turn influenced by family background and previous levels of trust (cf. Kahne et al. 2013)?

Model 1 in Table 6 shows that only the later conditions have significant effects on trust. Among these, tenure shows the strongest impact with those living in social housing having particularly low levels of trust by comparison to owner occupiers (the reference category). Also people renting privately have significantly lower levels of trust than the reference category. Educational attainment is also influential, as indicated by the significantly lower levels of trust of those with Level 1, NVQ level 2, and NVQ level 3 as highest qualification by comparison to those with a degree. Active participants are also significantly more trusting. One's current activity appears not to play a role as the trust levels of those in work or those in education are not significantly higher than the trust levels of those who do something else. Importantly, none of the social background indicators are significant, nor are 
ethnicity and gender. Model 2 confirms the insignificant effects of these variables. As this model does not include the later conditions, it is very unlikely that that the family background conditions have had an effect on trust as mediated through the later conditions. After all, Model 2 should then have shown significant direct effects of these variables. We also see that the explained variance jumps from a mere $2.1 \%$ in Model 2 to $9.3 \%$ in Model 1, which further underlines the weakness of the early childhood conditions and the power of the later conditions in accounting for the variation in trust at age 23. Of course, a total explained variance of $9.3 \%$ is still not impressive but this level of explained variance is not uncommon for analyses of generalized trust (e.g., Stolle and Hooghe 2004, p. 433; Wollebaek and Strømsnes 2008, p. 257).

Table 6. Determinants of generalized trust.

\begin{tabular}{|c|c|c|c|c|c|c|}
\hline & \multicolumn{2}{|c|}{ Model 1} & \multicolumn{2}{|c|}{ Model 2} & \multicolumn{2}{|c|}{ Model 3} \\
\hline & \multicolumn{2}{|c|}{ Generalized Trust } & \multicolumn{2}{|c|}{ Generalized Trust } & \multicolumn{2}{|c|}{ Generalized Trust } \\
\hline & Beta & (SE) & Beta & (SE) & Beta & (SE) \\
\hline $\begin{array}{l}\text { Education mother } \\
\text { Left full time education at 15/16 } \\
\text { Left after college or sixth form } \\
\text { Studied at university (ref cat) }\end{array}$ & $\begin{array}{l}-0.10 \\
-0.12\end{array}$ & $\begin{array}{l}(0.07) \\
(0.06)\end{array}$ & $\begin{array}{l}-0.08 \\
-0.10\end{array}$ & $\begin{array}{l}(0.07) \\
(0.06)\end{array}$ & $\begin{array}{l}-0.07 \\
-0.10\end{array}$ & $\begin{array}{c}0(0.07) \\
(0.07)\end{array}$ \\
\hline $\begin{array}{l}\text { Education father } \\
\text { Left full time education at 15/16 } \\
\text { Left after college or sixth form } \\
\text { Studied at university (ref cat) }\end{array}$ & $\begin{array}{l}-0.01 \\
-0.02\end{array}$ & $\begin{array}{l}(0.07) \\
(0.06)\end{array}$ & $\begin{array}{l}-0.05 \\
-0.05\end{array}$ & $\begin{array}{l}(0.07) \\
(0.06)\end{array}$ & $\begin{array}{l}-0.02 \\
-0.04\end{array}$ & $\begin{array}{l}(0.07) \\
(0.07)\end{array}$ \\
\hline Books at home & -0.03 & $(0.05)$ & 0.04 & $(0.05)$ & -0.01 & $(0.05)$ \\
\hline $\begin{array}{l}\text { Ethnic background } \\
\text { Asian } \\
\text { Black (ref cat for Model 3) } \\
\text { Other } \\
\text { White British (ref cat) }\end{array}$ & $\begin{array}{l}-0.08 \\
-0.06 \\
-0.01\end{array}$ & $\begin{array}{l}(0.04) \\
(0.04) \\
(0.04)\end{array}$ & $\begin{array}{l}-0.04 \\
-0.06 \\
-0.01\end{array}$ & $\begin{array}{l}(0.04) \\
(0.04) \\
(0.04)\end{array}$ & $\begin{array}{l}-0.07 \\
-0.05 \\
-0.00\end{array}$ & $\begin{array}{l}(0.04) \\
(0.04) \\
(0.04)\end{array}$ \\
\hline Gender $(1=$ boy; 2 = girl $)$ & 0.01 & $(0.04)$ & -0.01 & $(0.04)$ & -0.01 & $(0.04)$ \\
\hline $\begin{array}{l}\text { Educational attainment } \\
\text { Other qualifications } \\
\text { Level } 1 \\
\text { Level } 2 \text { vocational } \\
\text { Level } 2 \text { academic } \\
\text { Level } 3 \text { vocational } \\
\text { Level } 3 \text { academic } \\
\text { Level } 4 \text { vocational } \\
\text { Degree or higher (ref cat) }\end{array}$ & $\begin{array}{c}-0.05 \\
-0.1 * \\
-0.12^{* *} \\
-0.08 \\
-0.11^{*} \\
-0.02 \\
-0.07\end{array}$ & $\begin{array}{l}(0.04) \\
(0.04) \\
(0.04) \\
(0.04) \\
(0.04) \\
(0.04) \\
(0.04)\end{array}$ & & & $\begin{array}{c}-0.04 \\
-0.11^{*} \\
-0.10^{*} \\
-0.06 \\
-0.08 \\
-0.01 \\
-0.06\end{array}$ & $\begin{array}{l}(0.04) \\
(0.04) \\
(0.04) \\
(0.04) \\
(0.04) \\
(0.04) \\
(0.04)\end{array}$ \\
\hline $\begin{array}{l}\text { Tenure } \\
\text { Social rent, independent } \\
\text { Private rent, independent } \\
\text { Owner, living with parents } \\
\text { Renting, living with parents } \\
\text { Other living arrangement } \\
\text { Owner, independent (ref cat) }\end{array}$ & $\begin{array}{c}-0.16^{* *} \\
-0.15^{*} \\
-0.10 \\
-0.06 \\
-0.07\end{array}$ & $\begin{array}{l}(0.05) \\
(0.07) \\
(0.07) \\
(0.06) \\
(0.06)\end{array}$ & & & $\begin{array}{l}-0.15^{* *} \\
-0.14^{*} \\
-0.08 \\
-0.07 \\
-0.05\end{array}$ & $\begin{array}{l}(0.05) \\
(0.06) \\
(0.07) \\
(0.06) \\
(0.06)\end{array}$ \\
\hline $\begin{array}{l}\text { Current activity } \\
\text { Working } \\
\text { In education } \\
\text { Something else (ref cat) }\end{array}$ & $\begin{array}{c}0.03 \\
-0.06\end{array}$ & $\begin{array}{l}(0.05) \\
(0.05)\end{array}$ & & & $\begin{array}{c}0.05 \\
-0.04\end{array}$ & $\begin{array}{l}(0.05) \\
(0.05)\end{array}$ \\
\hline Active civic participation & $0.08^{*}$ & $(0.04)$ & & & $0.09 *$ & $(0.04)$ \\
\hline Generalized trust Wave 3 & & & & & $0.20^{* * *}$ & $(0.04)$ \\
\hline R square (\%) & & & & & & \\
\hline
\end{tabular}


Table 7. Determinants of educational attainment, tenure and active civic participation.

\begin{tabular}{|c|c|c|c|c|c|c|}
\hline & \multicolumn{2}{|c|}{ Having a Degree } & \multicolumn{2}{|c|}{$\begin{array}{l}\text { Social Rent, Living } \\
\text { Independently }\end{array}$} & \multicolumn{2}{|c|}{$\begin{array}{l}\text { Active Civic } \\
\text { Participation }\end{array}$} \\
\hline & Logit & (SE) & Logit & (SE) & Beta & (SE) \\
\hline $\begin{array}{l}\text { Education mother } \\
\text { Left full time education at } 15 \text { / } 16 \\
\text { Left after college or sixth form } \\
\text { Studied at university (ref cat) }\end{array}$ & $\begin{array}{l}-0.20 \\
-0.16\end{array}$ & $\begin{array}{l}(0.18) \\
(0.19)\end{array}$ & $\begin{array}{l}0.40 \\
0.44\end{array}$ & $\begin{array}{l}(0.47) \\
(0.45)\end{array}$ & $\begin{array}{c}-0.13 * \\
-0.11\end{array}$ & $\begin{array}{l}(0.06) \\
(0.06)\end{array}$ \\
\hline $\begin{array}{l}\text { Education father } \\
\text { Left full time education at } 15 \text { / } 16 \\
\text { Left after college or sixth form } \\
\text { Studied at university (ref cat) }\end{array}$ & $\begin{array}{l}-0.61 * * \\
-0.45^{*}\end{array}$ & $\begin{array}{l}(0.18) \\
(0.18)\end{array}$ & $\begin{array}{l}0.77 \\
0.90\end{array}$ & $\begin{array}{l}(0.52) \\
(0.49)\end{array}$ & $\begin{array}{l}0.03 \\
0.04\end{array}$ & $\begin{array}{l}(0.06) \\
(0.06)\end{array}$ \\
\hline Books at home & $0.23^{* * *}$ & $(0.05)$ & -0.09 & $(0.08)$ & $0.16^{* * *}$ & $(0.05)$ \\
\hline $\begin{array}{l}\text { Ethnic background } \\
\text { Asian } \\
\text { Black (ref cat) } \\
\text { Other } \\
\text { White British }\end{array}$ & $\begin{array}{l}1.29 \\
1.28 \\
0.85\end{array}$ & $\begin{array}{l}(0.70) \\
(0.73) \\
(0.68)\end{array}$ & $\begin{array}{l}4.95 \\
5.58 \\
5.24\end{array}$ & $\begin{array}{l}(4.56) \\
(5.56) \\
(4.98)\end{array}$ & $\begin{array}{c}0.08 \\
0.03 \\
-0.04\end{array}$ & $\begin{array}{l}(0.11) \\
(0.07) \\
(0.11)\end{array}$ \\
\hline Gender $(1=$ boy; 2 = girl $)$ & 0.19 & $(0.11)$ & $0.56^{* * *}$ & $(0.02)$ & $-0.17^{* * *}$ & $(0.04)$ \\
\hline Generalized trust wave 3 & $0.19^{*}$ & $(0.08)$ & -0.06 & $(0.16)$ & -0.04 & $(0.04)$ \\
\hline R square (\%) & & & & & & \\
\hline
\end{tabular}

These influences, moreover, hardly change when trust at age 16 is added to the analysis (Model 3). Although prior levels of trust show a very strong effect on trust at age 23, they do not neutralize the effects of educational attainment, tenure and active civic participation. This suggests that these later conditions indeed make trust change post 16 (keeping in mind that we cannot make conclusive claims about causality, as discussed earlier).

Figures 2-4 illustrate these effects vividly. They show the development of trust between age 16 and 23 by highest qualification, form of tenure and degree of civic participation. Categories of each of these variables were merged to facilitate interpretation. ${ }^{2}$ Across time trust levels appear to diverge between the categories of all three variables. When we look at education we see that the level of trust was highest at age 16 and has remained quite stable since for those who have obtained a degree by the age of 23. In contrast, the initial trust level was lowest and shows the steepest decline for those who had a degree of lower secondary as their highest qualification obtained at age 23 . The pattern for tenure is a bit different due to the slump in trust at age 20 for independent owners. Yet trust among this group recovers quickly so that by age 23 they show the highest level of trust. All three groups show a decline in trust but the decline is most pronounced among tenants (who were least trusting at age 16 anyway) and shallowest among independent owners. By age 23 differences in trust between the three groups are larger than they were at age 16. This trend is even more pronounced when we look at groups varying in levels of civic participation. At age 16 these groups have almost similar trust levels but soon after trust starts to fall dramatically for those who do not take part in any club or group. In contrast, trust rises slightly amongst those participating in one or several groups. By age 23 a large gap has emerged between participants and non-participants. Thus on all three variables we see widening gaps, with the poorly educated, tenants and non-participants drifting away from the rest in terms of their (low) trust levels.

2 These figures are based on the longitudinal sample. As this sample suffers from selective attrition (as noted before), the results should not be understood as nationally representative. 
"How much do you trust people of your own age?" (\% quite a lot \& completely)

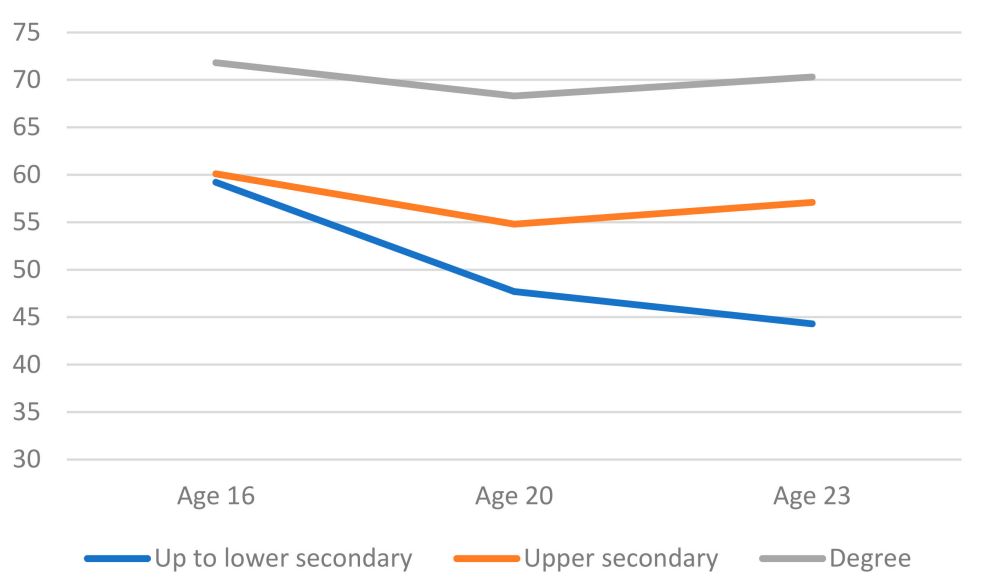

Figure 2. Generalized trust by highest qualification achieved.

"How much do you trust people of your own age?" (\% quite a lot \& completely)

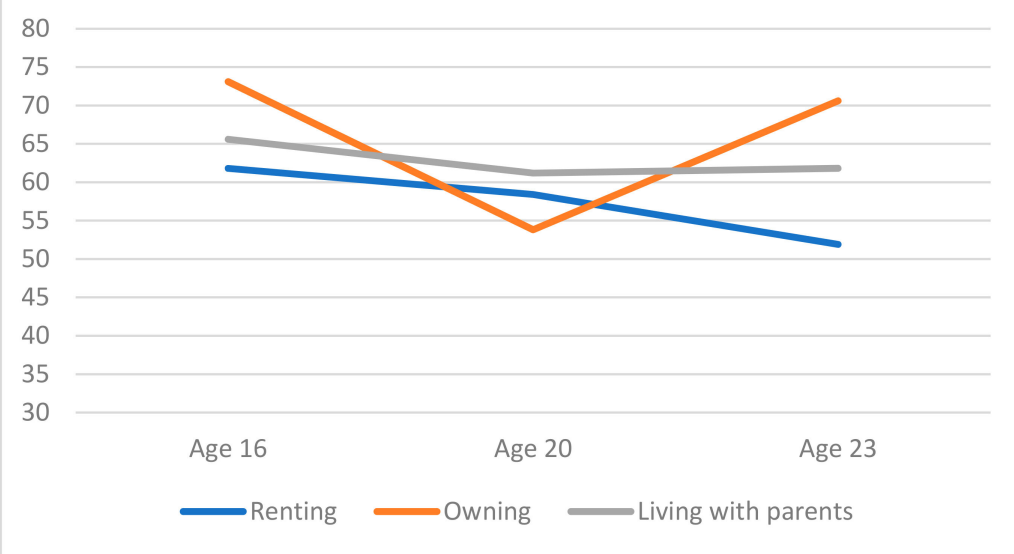

Figure 3. Generalized trust by tenure and living arrangement.

"How much do you trust people of your own age?" (\% quite a lot $\&$ completely)

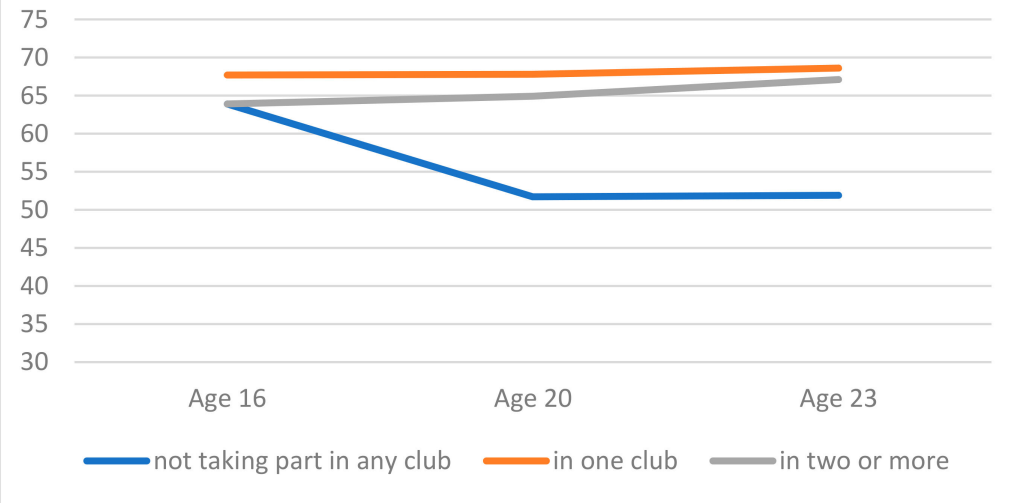

Figure 4. Generalized trust by active civic participation. 


\subsection{The Determinants of Educational Attainment, Tenure and Civic Participation}

However, we cannot conclusively prove that the causal arrow runs exclusively from the later conditions to trust as these independent variables and the outcome variable were measured at the same point in time and it is thus always possible that high levels of pre-existing trust have helped people to attain good qualifications, become civically engaged and find a secure form of living. Table 7 helps to assess these possible reciprocal effects. We focus on social renting (by comparison to other forms of tenure), having a degree (in relation to other qualifications) and active participation as outcomes. Logistic regressions were carried out on the first two outcomes in view of their binary nature, linear regression on the last one. The models show that those who managed to obtain a degree have higher levels of trust at age 16, have better educated fathers and have higher levels of home resources (i.e., books at home). Living in social housing is only influenced by gender, with women experiencing this form of tenure in much larger numbers than men. This might indicate the high prevalence of lone parent families (which are often headed by women) in this form of tenure. Similar to having a degree, being an active participant is influenced by social background factors, although this time the education level of the mother appears to matter. In sum, there is certainly some evidence of reciprocal causation for educational attainment. Educational attainment and active civic participation are further both influenced by social background. Tenure is more immune to prior influences.

\section{Discussion}

This paper sought to provide a comprehensive account of generalized trust among young people in England today. In view of the many individual and societal benefits that generalized trust produces, it is an important asset worth maintaining and nourishing. In this regard the current state of affairs is disconcerting. Not only do young people today show quite low levels of generalized trust, certainly in comparison to other forms of social trust, but their trust levels are also much lower than those of older age groups.

We focused on trust in people of one's own age as measure of generalized trust. A principle component analysis found this measure to load strongly on a dimension that also incorporated trust in people of a different religion and nationality, people you meet for the first time and the well-known item "most people can be trusted", the usual indicator of generalized trust. Using this measure, we found trust to be anything but stable between the ages of 12 and 23. Although trust appeared to become less volatile towards the end of that age span, still only 12 percent of trust at age 23 was explained by trust at age 20. Moreover, an analysis of the determinants of trust at age 23 showed that only conditions experienced during late adolescence and early adulthood had significant effects on trust. None of the indicators of social and ethnic background, representing early childhood influences, were related to trust, neither in an analysis with nor in one without the conditions pertaining to late adolescence. Among these later conditions, tenure, educational attainment and active civic participation were particularly influential. Trust between ages 16 and 23 declined faster amongst non-graduates compared to graduates and among non-participants compared to those participating in one or two civic organizations. It further truly plummeted among people living in social housing or renting privately compared to those with other forms of tenure or living arrangements. Thus, these conditions made young people drift further apart in their trust levels after age 16. We did find social and ethnic background to influence educational attainment and civic participation, indicating that these conditions do have some indirect effect on trust. This indirect effect must be quite diluted, however, as social and ethnic background were not related to trust in a model without educational attainment, civic participation and tenure.

In sum, these findings provide strong support for the social learning perspective. Based on the findings about the family background variables, one might be tempted to conclude that there is no support for the idea that trust is mainly shaped in early childhood. However, we have tapped family background with only two variables (parental education and books at home) since no other indicators of early childhood socialization are available. Possibly, we would have found more support for the 
early childhood perspective if we could have explored the effect of household composition, parental occupation, income and health. Nonetheless, the findings are encouraging in that they suggest that low levels of trust developed in childhood can be ameliorated later on. They are in agreement with Flanagan and Stout (2010), who found that social trust was still dynamic among mid to late adolescents and was strongly related to respondents' sense of solidarity in school and opportunities to engage in free discussions. They also tally with Abdelzadeh and Lundberg (2017), who reported on a Swedish longitudinal study and also found generalized trust to be relatively volatile in early to mid-adolescence and to become more stable in early adulthood.

In terms of policy recommendations our findings might at first sight suggest that raising education levels, fostering civic participation and improving the conditions of tenants are effective measures to promote trust. Several qualifications need to be made here, however. Firstly, it is not sure whether raising the education level of people will also make them more trusting in the aggregate. If education has a direct and thus absolute effect on trust, this should happen. If the effect is positional, however, education only influences trust indirectly by improving the competitive position of individuals. In that case rising education levels are a zero-sum game with one individual's gain in education automatically entailing the loss of status of an individual whose education level stayed the same. In such a scenario educational expansion will not lead to a rise in aggregate trust levels. Campbell (2006) claims that the effect of education on generalized trust is even beyond absolute, namely cumulative. This means that education is contagious: the more you are surrounded by well-educated people, the more trusting you become irrespective of your own education level. However, neither Campbell nor those who claim that the effect of education is absolute can explain why young people have the lowest levels of trust of all age groups despite being better educated than any generation before them. It might still be possible that education has had an absolute or even cumulative effect on trust but then this positive effect must have been overwhelmed by other more powerful negative influences. Possibly rising inequality, the contraction of the welfare state or the economic crisis hitting young people particularly hard constitute such negative forces.

Secondly, education is not a wholly exogenous factor as we found trust at age 16 to influence highest qualification obtained at age 23. There are thus reciprocal effects between education and trust casting doubt on the ability of education to independently enhance trust.

Thirdly, we find social background to be an important determinant of both educational attainment and civic participation. There is of course nothing new about this finding. Intergenerational continuity in educational attainment has been well documented in the literature, as has the link between SES and civic engagement (e.g., Verba et al. 1995; Schulz et al. 2010; Lauglo 2011). However, it does mean that these trust-enhancing factors are less amenable to change than positive influences on trust that are not so dependent on social background.

Perhaps the most surprising and at the same time encouraging finding of this paper is the strong independent effect of tenure on generalized trust. Although we find, as the few other studies who looked into this, that independent home owners have the highest levels of trust, our results are innovative in that they show tenure to be the only influential factor not affected by social or ethnic background or prior levels of trust. Our study has not addressed the mechanisms linking tenure to trust. Is it primarily through the more extended social networks ('bridging social capital') of homeowners or through a possibly greater sense of insecurity experienced by tenants renting privately that tenure influences trust? It may well be through the former since all tenants showed lower trust levels, not just the ones renting privately. Additionally, there is always the possibility that tenancy proxies for some socio-economic background condition (e.g., family wealth) that the present study has not been able to observe. Future research could examine these outstanding issues. Provisionally our findings suggest that policies aiming to improve the conditions of those renting from private landlords or the council, as the categories with the lowest trust levels, can be quite effective in enhancing trust. Such policies could include enhancing the legal status of private tenants, or, given the recent Grenfell disaster, ensuring that all existing fire and safety regulations are rigorously enforced for council housing. 
We have to end on two cautionary notes. The first concerns the very high level of attrition in the data source. Because of this we cannot claim that the findings are in any way representative of England as a whole. However, lack of representativeness is a feature of many studies using either longitudinal or cross-sectional date. This does not necessarily invalidate such studies, particularly not when the data used shows meaningful variation on the variables of interest, which it does in our case. Secondly, using trust in people of one's own age as indicator of generalized trust is not ideal. Although this indicator showed a much stronger loading on a generalized trust factor than on a factor reflecting particularized trust, the loading on the latter was still 0.44. It is a task of future research to examine whether the same trends and explanatory patterns can be observed using less ambivalent measures of generalized trust, such as trust in strangers or the well-known 'most people can be trusted' item.

Funding: This research was funded by ESRC (LLAKES Phase II; grant number ES/J019135/1).

Conflicts of Interest: The author declares no conflict of interest.

\section{References}

Abbott, Stephen, and Della Freeth. 2008. Social capital and health starting to make sense of the role of generalized trust and reciprocity. Journal of Health Psychology 13: 874-83. [CrossRef] [PubMed]

Abdelzadeh, Ali, and Erik Lundberg. 2017. Solid or Flexible? Social Trust from Early Adolescence to Young Adulthood. Scandinavian Political Studies 40: 207-27. [CrossRef]

Alderman, Harol, Jere Behrman, Hans-Peter Kohler, John Maluccio, and Susan Cotts Watkins. 2001. Attrition in Longitudinal Household Survey Data. Demographic Research 5: 79-124. [CrossRef]

Benton, Tom, David Kerr, and Joana Lopes. 2008. Citizenship Education Longitudinal Study (CELS): Sixth Annual Report Young People's Civic Participation in and Beyond School: Attitudes, Intentions and Influences. London: DCSF.

Bjørnskov, Christian. 2007. Determinants of generalized trust: A cross-country comparison. Public Choice 130: 1-21. [CrossRef]

Bjørnskov, Christian. 2012. How does social trust affect economic growth? Southern Economic Journal 78: 1346-68. [CrossRef]

Brehm, John, and Wendy Rahn. 1997. Individual-level evidence for the causes and consequences of social capital. American Journal of Political Science 41: 999-1023. [CrossRef]

Burt, Ronald. 2005. Brokerage and Closure: In Introduction to Social Capital. Oxford: Oxford University Press.

Campbell, David. 2006. What is education's impact on civic and social engagement? In Measuring the Effects of Education on Health and Civic/Social Engagement. Edited by Richard Desjardins and Tom Schuller. Paris: OECD/CERI, pp. 25-126.

Claibourn, Michele P., and Paul S. Martin. 2000. Trusting and Joining? An Empirical Test of the Reciprocal Nature of Social Capital. Political Behaviour 22: 267-91. [CrossRef]

Delhey, Jan, and Kenneth Newton. 2003. Who Trusts? The Origins of Social Trust in Seven Societies. European Societies 5: 93-137. [CrossRef]

DiPasquale, Denise, and Edward Glaeser. 1998. Incentives and Social Capital: Are Homeowners Better Citizens? NBER Working Paper 6363. Cambridge: Harvard University and NBER.

Ferraro, Kenneth. 1995. Fear of Crime. Albany: State University Press of New York.

Finkel, Steven. 1995. Causal Analysis with Panel Data. Thousand Oaks: Sage.

Flanagan, Constance, and Michael Stout. 2010. Developmental patterns of social trust between early and late adolescence: Age and school climate effects. Journal of Research on Adolescence 20: 748-73. [CrossRef]

Gambetta, Diego. 1988. Can we trust trust? In Trust: Making and Breaking Cooperative Relations. Edited by Diego Gambetta. Oxford: Basil Blackwell.

Glanville, Jennifer, and Pamela Paxton. 2015. How Do We Learn to Trust?: A Confirmatory Tetrad Analysis of the Sources of Generalized Trust. ASA Working paper. Washington: American Sociological Association.

Green, Andy, Jan Germen Janmaat, and Helen Cheng. 2011. Social cohesion: Converging and diverging trends. National Institute Economic Review 215: 8-23. [CrossRef]

Hardin, Russell. 1999. Do we want to trust in government? In Democracy and Trust. Edited by Mark Warren. Cambridge: Cambridge University Press, pp. 22-41. 
Hirashi, Kai, Shinji Yamagata, Chizuru Shikishima, and Juku Ando. 2008. Maintenance of genetic variation in personality through control of mental mechanisms: A test of trust, extraversion and agreeableness. Evolution and Human Behavior 29: 79-85. [CrossRef]

Howker, Ed, and Shiv Malik. 2013. Jilted Generation: How Britain has Bankrupted Its Youth. London: Icon Books.

Huang, Jian, Henriette Maassen van den Brink, and Wim Groot. 2009. A meta analysis of the effect of education on social capital. Economics of Education Review 28: 454-64. [CrossRef]

Huang, Jian, Henriette Maassen van den Brink, and Wim Groot. 2011. College Education and Social Trust: An Evidence-Based Study on the Causal Mechanisms. Social Indicators Research 104: 287-310. [CrossRef] [PubMed]

Janmaat, Jan Germen. 2016. Values in times of austerity: A cross-national and cross-generational analysis. Citizenship Teaching and Learning 11: 267-87. [CrossRef]

Kahne, Joseph, David Crow, and Nam Jin Lee. 2013. Different Pedagogy, Different Politics: High School Learning Opportunities and Youth Political Engagement. Political Psychology 34: 419-41. [CrossRef]

King, Hannah. 2015. Young people and the predictability of precarious transitions. In Defense of Welfare 2. Edited by Liam Foster, Anne Brunton, Chris Deeming and Tina Haux. York: The Social Policy Organisation, pp. 143-45.

Knack, Stephen, and Phillip Keefer. 1997. Does social capital have an economic pay-off? A cross-country investigation. Quarterly Journal of Economics 112: 1251-88. [CrossRef]

Knack, Stephen, and Paul Zak. 2002. Building trust: Public policy, interpersonal trust, and economic development. Supreme Court Economic Review 10: 91-107. [CrossRef]

Lauglo, Jon. 2011. Political socialization in the family and young people's educational achievement and ambition. British Journal of the Sociology of Education 32: 53-74. [CrossRef]

Laurence, James. 2015. (Dis)placing Trust: The Long-Term Effects of Job Displacement on Generalized Trust over the Adult Lifecourse. Social Science Research 50: 46-59. [CrossRef]

Li, Yaojun, Andrew Pickles, and Mike Savage. 2005. Social capital and social trust in Britain. European Sociological Review 21: 109-23. [CrossRef]

Lindström, Martin. 2009. Psychosocial work conditions, unemployment, and generalized trust in other people: A population-based study of psychosocial health determinants. The Social Science Journal 46: 584-93. [CrossRef]

Lopaciuk-Gonczaryk, Beata. 2019. Does participation in social networks foster trust and respect for other people-Evidence from Poland. Sustainability 11: 1733. [CrossRef]

Manturuk, Kim, Mark Lindblad, and Roberto Quercia. 2010. Friends and Neighbours: Homeownership and Social Capital among Low-to Moderate-Income Families. Journal of Urban Affairs 32: 471-88. [CrossRef]

Matthews, Peter, and Kirsten Besemer. 2015. Social networks, social capital and poverty: Panacea or placebo? Journal of Poverty and Social Justice 23: 189-201. [CrossRef]

Muthen, Linda, and Bengt Muthen. 2009. Mplus User's Guide, 5th ed. Muthen \& Muthen: Los Angeles.

Oskarsson, Sven, David Cesarini, Christopher Dawes, James Fowler, Magnus Johannesson, Patrik Magnusson, and Jan Teorell. 2015. Linking Genes and Political Orientations: Testing the Cognitive Ability as Mediator Hypothesis. Political Psychology 36: 649-65. [CrossRef]

Paterson, Lindsay. 2013. Comprehensive education, social attitudes and civic engagement. Longitudinal and Life Course Studies 4: 17-32.

Paxton, Pamela. 1999. Is Social Capital Declining in the United States? A Multiple Indicator Assessment. American Journal of Sociology 105: 88-127. [CrossRef]

Paxton, Pamela. 2007. Association memberships and generalized trust: A multilevel model across 31 countries. Social Forces 86: 47-76. [CrossRef]

Pilkington, Hillary, and Gary Pollock. 2015. "Politics are bollocks": Youth, politics and activism in contemporary Europe. The Sociological Review 63: 1-35. [CrossRef]

Putnam, Robert. 1993. Making Democracy Work: Civic Traditions in Modern Italy. Princeton: Princeton University Press. Putnam, Robert. 2000. Bowling Alone: The Collapse and Revival of American Community. New York: Simon and Schuster. Putnam, Robert. 2007. E pluribus unum: Diversity and community in the twenty-first century, the 2006 Johan Skytte Prize Lecture. Scandinavian Political Studies 30: 137-74. [CrossRef]

Rotter, Julian. 1971. Generalized Expectancies for Interpersonal Trust. American Psychologist 26: 443-50. [CrossRef]

Schulz, Wolfram, John Ainly, Julian Fraillon, David Kerr, and Bruno Losito. 2010. ICCS 2009 International Report: The Civic Knowledge, Attitudes and Engagement among Lower Secondary School Students in 38 Countries. Amsterdam: IEA. 
Shildrick, Tracy, Robert MacDonald, Colin Webster, and Kayleigh Garthwaite. 2012. Poverty and Insecurity: Life in Low-Pay, No-Pay Britain. Bristol: Policy Press.

Stack, Lois C. 1978. Trust. In Dimensions of Personality. Edited by Harvey London and John Exner. New York: John Wiley and Sons, pp. 561-99.

Stolle, Dietlind. 2003. The Sources of Social Capital. In Generating Social Capital: Civil Society and Institutions in Comparative Perspective. Edited by Dietlind Stolle and Marc Hooghe. New York: Palgrave Macmillan, pp. $19-42$.

Stolle, Dietlind, and Marc Hooghe. 2004. The Roots of Social Capital: Attitudinal and Network Mechanisms in the Relation between Youth and Adult Indicators of Social Capital. Acta Politica 39: 422-41. [CrossRef]

Stolle, Dietlind, and Thomas Rochon. 1998. Are All Associations Alike? Member Diversity, Associational Type and the Creation of Social Capital. American Behavioral Scientist 42: 47-65. [CrossRef]

Stubager, Rune. 2008. Education effects on authoritarian-libertarian values: A question of socialization. British Journal of Sociology 59: 327-50. [CrossRef] [PubMed]

Sturgis, Patrick, Sanna Read, Peter Hatemi, Gu Shu, Tim Trull, Margaret Wright, and Nicholas Martin. 2010. A genetic basis for social trust? Political Behavior 32: 205-30. [CrossRef]

Sturgis, Patrick, Roger Patulny, Nick Allum, and Franz Buscha. 2012. Social Connectedness and Generalized Trust: A Longitudinal Study. ISER Working Paper Series; Wollongong: University of Wollongong.

Tyler, Imogen. 2013. Revolting Subjects: Social Abjection and Resistance in Neoliberal Britain. London: Zed Books.

Uslaner, Eric M. 2002. The Moral Foundations of Trust. Cambridge: Cambridge University Press.

Uslaner, Eric M., and Mitchell Brown. 2005. Inequality, trust, and civic engagement. American Politics Research 33: 868-94. [CrossRef]

Verba, Sidney, Kay Lehman Schlozman, and Henry Brady. 1995. Voice and Equality: Civic Voluntarism in American Politics. Cambridge: Harvard University Press.

Waters, Lea. 2007. Experiential differences between voluntary and involuntary job redundancy on depression, job-search activity, affective employee outcomes and re-employment quality. Journal of Occupational and Organizational Psychology 80: 279-99. [CrossRef]

Wolke, Dieter, Andrea Waylen, and Muthanna Samara. 2009. Selective drop-out in longitudinal studies and non-biased prediction of behaviour disorders. British Journal of Psychiatry 195: 249-56. [CrossRef]

Wollebaek, Dag, and Kristin Strømsnes. 2008. Voluntary associations, trust and civic engagement: A multi-level approach. Nonprofit and Voluntary Sector Quarterly 37: 249-63. [CrossRef]

Wrightsman, Lawrence. 1992. Assumptions about Human Nature: Implications for Researchers and Practitioners. Newbury Park: Sage.

Wuthnow, Robert. 1997. The Role of Trust in Civic Renewel. Working Paper \#1. College Park: National Commission on Civic Renewal.

(C) 2019 by the author. Licensee MDPI, Basel, Switzerland. This article is an open access article distributed under the terms and conditions of the Creative Commons Attribution (CC BY) license (http://creativecommons.org/licenses/by/4.0/). 